\title{
Sauropod and Small Theropod Tracks from the Lower Jurassic Ziliujing Formation of Zigong City, Sichuan, China, with an Overview of Triassic-Jurassic Dinosaur Fossils and Footprints of the Sichuan Basin
}

\author{
Lida Xing, ${ }^{1}$ Guangzhao Peng, ${ }^{2}$ Yong Ye, ${ }^{2}$ Martin G. Lockley, ${ }^{3}$ Hendrik Klein, ${ }^{4}$ W. Scott Persons IV, \\ Jianping Zhang, ${ }^{1}$ Chunkang Shu, ${ }^{2}$ and Baoqiao $\mathrm{Hao}^{2}$ \\ ${ }^{1}$ School of the Earth Sciences and Resources, China University of Geosciences, Beijing, China \\ ${ }^{2}$ Zigong Dinosaur Museum, Zigong, Sichuan, China \\ ${ }^{3}$ Dinosaur Trackers Research Group, University of Colorado, Denver, Colorado, USA \\ ${ }^{4}$ Saurierwelt Paläontologisches Museum, Neumarkt, Germany \\ ${ }^{5}$ Department of Biological Sciences, University of Alberta, Edmonton, Alberta, Canada
}

A dinosaur footprint assemblage from the Lower Jurassic Ziliujing Formation of Zigong City, Sichuan, China, comprises about 300 tracks of small tridactyl theropods and large sauropods preserved as concave epireliefs (natural molds). The theropod footprints show similarities with both the ichnogenera Grallator and Jialingpus. Three different morphotypes are present, probably related to different substrate conditions and extramorphological variation. A peculiar preservational feature in a morphotype that reflects a gracile trackmaker with extremely slender digits, is the presence of a convex epirelief that occurs at the bottom of the concave digit impressions. It is possibly the result of sediment compaction underweight load when the pes penetrated the substrate, being a resistant residue during exhumation and weathering. The sauropod tracks belong to a trackway with eight imprints consisting of poorly preserved pes and manus tracks and a better preserved set, probably all undertracks. The narrow-gauge trackway pattern resembles the ichnogenus Parabrontopodus well known from the Jurassic but other features such as the minor heteropody are different. The assemblage enriches the dinosaur record from the famous Zigong locality and the evidence from the Lower Jurassic in this area that was restricted to a few skeletal remains and footprints. Furthermore it proves the presence of small theropods, whereas skeletons of the group, well- known from the Middle-Upper Jurassic of Zigong, are of medium to large size only. Remarkable is the dominance of saurischians in these assemblages, which is characteristic of Jurassic dinosaur communities whereas the Cretaceous record shows an increase of ornithopod groups. An overview of the dinosaur trace and body fossil record of the Sichuan Basin supports this view. The paleoenvironment can be designated as a low-latitude tropical freshwater lake as it is indicated by bivalve shells.

Address correspondence to Lida Xing, School of the Earth Sciences and Resources, China University of Geosciences, Beijing 100083, China. E-mail: Xinglida@gmail.com
Keywords Grallator, Parabrontopodus, Hejie tracksite, Ma'anshan Member, Zigong

\section{INTRODUCTION}

Zigong is famous for the Middle Jurassic Shunosaurus fauna and the Late Jurassic Mamenchisaurus fauna. However, fossils from the Early Jurassic and the Late Triassic are comparatively rare. Previously reported Early Jurassic fossils include fragmentary prosauropod and sauropod skeletal remains as well as Grallator tracks (Peng et al., 2005). Late Triassic fossils include a recently reported archosaur trackway of uncertain affinity (Xing et al., in press a).

In 1972, Junlin Ye discovered dinosaur tracks at Hejie street, Gongjing District, Zigong City (Fig. 1). In 1996, these tracks were collected by the Zigong Dinosaur Museum. Peng et al. (2005) assigned the tracks to Grallator s-satoi, (correctly G. ssatoi according to International Code of Zoological Nomenclature rules). In 2011 and 2012, the lead authors (LX and GP) investigated the collected tracks and the original tracksite. The material comprises 300 individual footprints, all tridactyl theropod tracks and consistent in general morphology (Peng et al., 2012). In 2013, sauropod tracks were recognized when the material was further cleared and prepared in the lab. Herein, these tracks are described in detail.

\section{GEOLOGIC SETTING}

Based on vertebrate fossils, Peng et al. (2005) give a stratigraphic sequence for the dinosaur faunas of the Zigong area (see also Lucas, 2001). Their scheme identifies two formations (Zhenzhuchong and Ziliujing) as Lower Jurassic, two formations (Xintiangou and Xiashaximiao) as Middle Jurassic 

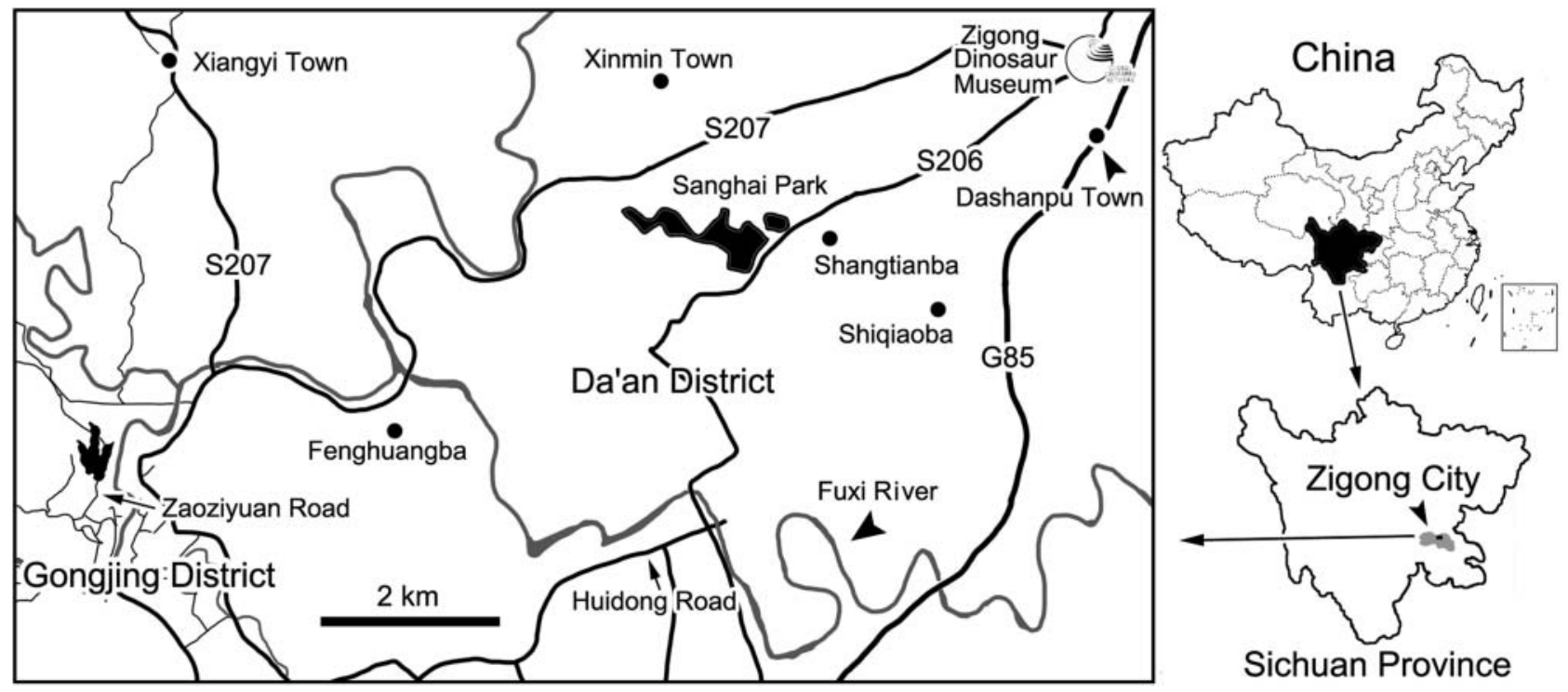

FIG. 1. Map showing the position of the footprint locality (footprint icon), the Hejie tracksite, Zigong City, Sichuan Province, China.

and three formations (Shangshaximiao, Suining and Penglaizhen) as Upper Jurassic (Fig. 2).

The track-bearing Lower Jurassic Ziliujing Formation is restricted in its distribution throughout the Zigong area. It is composed of terrigenous clastic sediments and a few carbonate sediments, and its total thickness is approximately $182 \mathrm{~m}$. In lithology, the Ziliujing Formation is divided into three members: the lower Dongyuemiao Member, the middle Ma'anshan Member and the upper Da'anzhai Member. The Hejie tracksite is located in the Ma'anshan Member (Fig. 2). The thickness of the Ma'anshan Member is approximately $131-180 \mathrm{~m}$. The lower part is predominantly composed of purple-red mudstone, mixed with layers of light yellow and yellowish green quartz siltstone, the middle part of gray-green and yellowish green quartz siltstone and the upper portion of purple-red mudstone universally mixed with calcareous beds and banded siltstone. In addition to dinosaur tracks, invertebrate fossils, such as bivalve shells, are known from the Ma'anshan Member. The dinosaur tracks come from a layer between the upper mudstones and middle siltstones. The track bearing sediments are rich in calcareous cement functioning as a strong binder between the different sedimentary layers. The paleoenvironment can be designated as a low-latitude tropical freshwater lake as it is indicated also by the bivalve shells.

\section{SYSTEMATIC ICHNOLOGY}

\section{Theropod Tracks}

Material: More than 300 footprints, distributed on two slabs (fractured into seven larger pieces and five smaller pieces) (Fig. 3). The 253 footprints preserved on the seven larger pieces are numbered as ZDM00139-T1-253.

Locality and horizon: The Ma'anshan Member of the Ziliujing Formation, Lower Jurassic. Hejie tracksite, Zigong City, Sichuan Province, China.

Description and comparison: Based on size and preservation, the theropod tracks can be divided into three general types.

Type A: Natural mold tridactyl theropod tracks (Figs. 4A, $5 \mathrm{~A}, 6 \mathrm{~A})$. These range from 11 to $15 \mathrm{~cm}$ in length. T1-T3 constitute a single trackway with an individual pace length of 61.7 and $62.6 \mathrm{~cm}$, a stride length of $124.0 \mathrm{~cm}$, and a pace angulation of $172^{\circ}$ (Fig. 6A). The average length:width ratio of the imprints is 1.67. A characteristic feature of their preservation is that digits are isolated from each other. The average divarication angle between digits II and IV is $51^{\circ}$. Digit III is straight and the longest, digit II the shortest. The pad formula of digits II-IV is 2-3-4. Claw marks are sharp. The proximal edge of the phalangeal pad 1 on digit II is abreast of the distal edge of the metatarsophalangeal pad (pad 1) on digit IV. The metatarsophalangeal pad of digit IV is slightly displaced laterally with respect to the axis of digit IV giving the trace of digit IV a curved appearance.

Type B: T10-T19 are well-preserved natural mold tridactyl theropod tracks (Fig. 4B). No well-defined trackways have been observed. Other characteristics are consistent with Type A, except as follows. Tracks range from 6 to $8 \mathrm{~cm}$ in length. The average length: width ratio is 1.36 . Most imprints show three separated digit traces, except of T13 and T19 where the metatarsophalangeal area contacts digits II and IV. Digit II and III impressions are equally deep, but that of digit IV is shallower. In some less well-preserved tracks, the metatarsophalangeal pad of digit IV is absent and in some instances the 


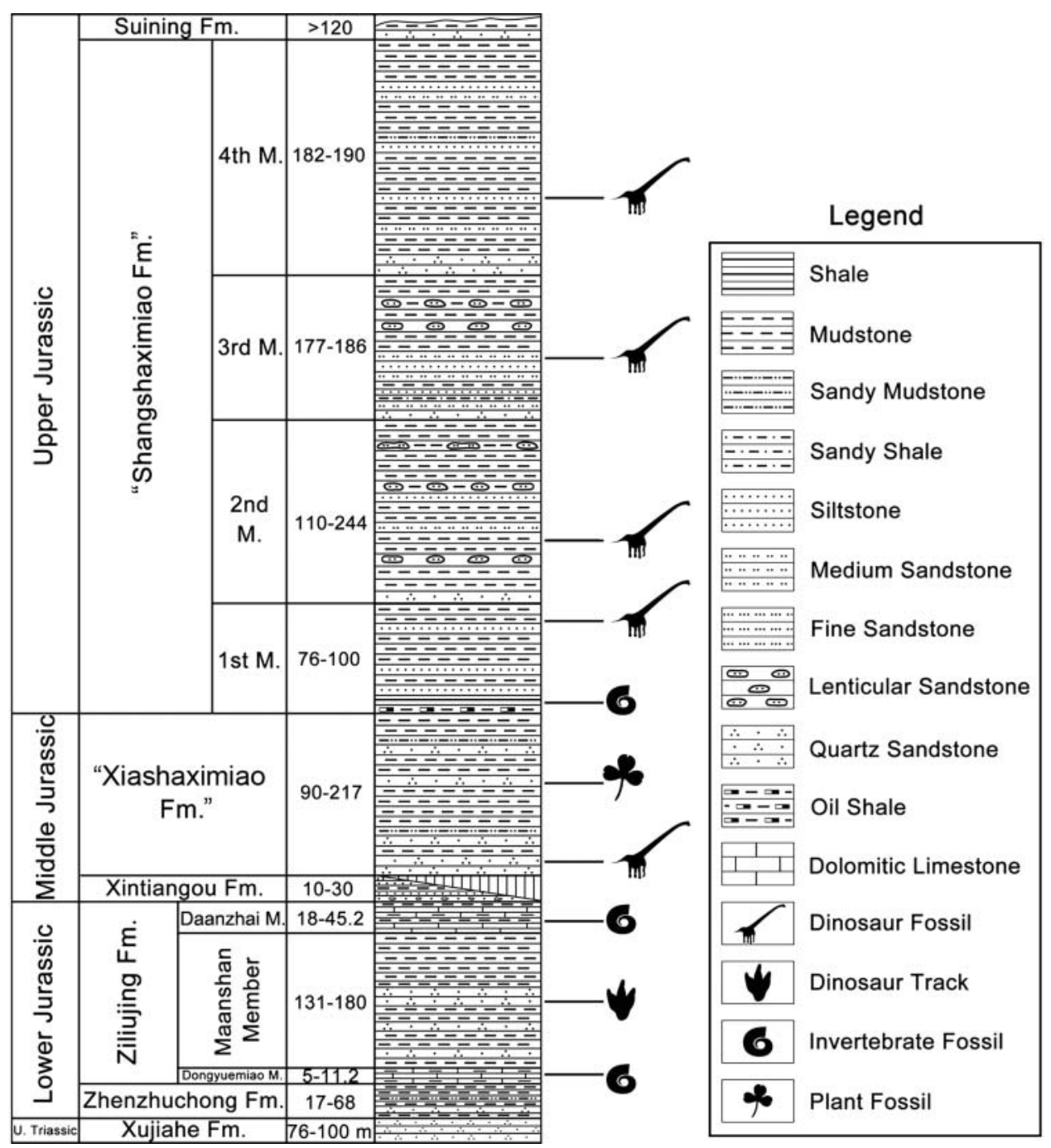

FIG. 2. Stratigraphic section of the Jurassic in the study area with the position of footprints and body fossil remains.

digit IV trace is smaller or completely absent. The average divarication angle between digits II and IV is $74^{\circ}$ (larger than in Type A). The calculation of the divarication angle is complicated by the occasional reduction or absence of digit IV traces. T11 and T19 have well-preserved digit IV impressions and divarication angles of $56^{\circ}$ and $54^{\circ}$, respectively, which is consistent with Type A.

Type C: T20-T27 are well-preserved natural mold tridactyl theropod tracks (Figs. 4C and 5B) from the upper bed surface that show a convex epirelief in the center. Their length ranges from 6 to $8 \mathrm{~cm}$. The average length: width ratio is 1.10 , but is very variable due to differences in preservation (Table 1). All three digits are separated, and have a slender shape. When preserved (as in T21, T22, T26) digit III has three digital pad traces. The lengths of digits II and IV (relative to digit III) are smaller than in well-preserved tracks of type B, but they are similar to poorly-preserved tracks of type B (such as T16 and T18). The average divarication angle between digit II and digit
IV is $95^{\circ}$. Partial tracks (such as T21 and T23) exhibit characteristics similar to bird tracks, including slender digits and wide divarication angles, which are both enhanced by the preservational conditions.

Type $\mathrm{C}$ is similar to type $\mathrm{B}$ in size, but quite different in preservation. Well-preserved type $\mathrm{C}$ tracks have shallow lateral concave margins (as in T21 and T22), and are similar to type B mold tracks in their morphology; however, the bottom of the type $\mathrm{C}$ tracks is slightly convex. Type $\mathrm{B}$ and $\mathrm{C}$ are preserved on the same surface, but the type $\mathrm{C}$ tracks appear to have been made earlier. As discussed below, the differences between the impression of type $\mathrm{C}$ and type $\mathrm{B}$ tracks mean that the elastic or moisture properties of sediments must have differed. The convex interior part remained in the molds withstanding the later exposure and weathering.

Discussion: All 24 currently known Chinese theropod ichnospecies known from the Early or Middle Jurassic of China can be assigned to one of five ichnogenera: Changpeipus, 


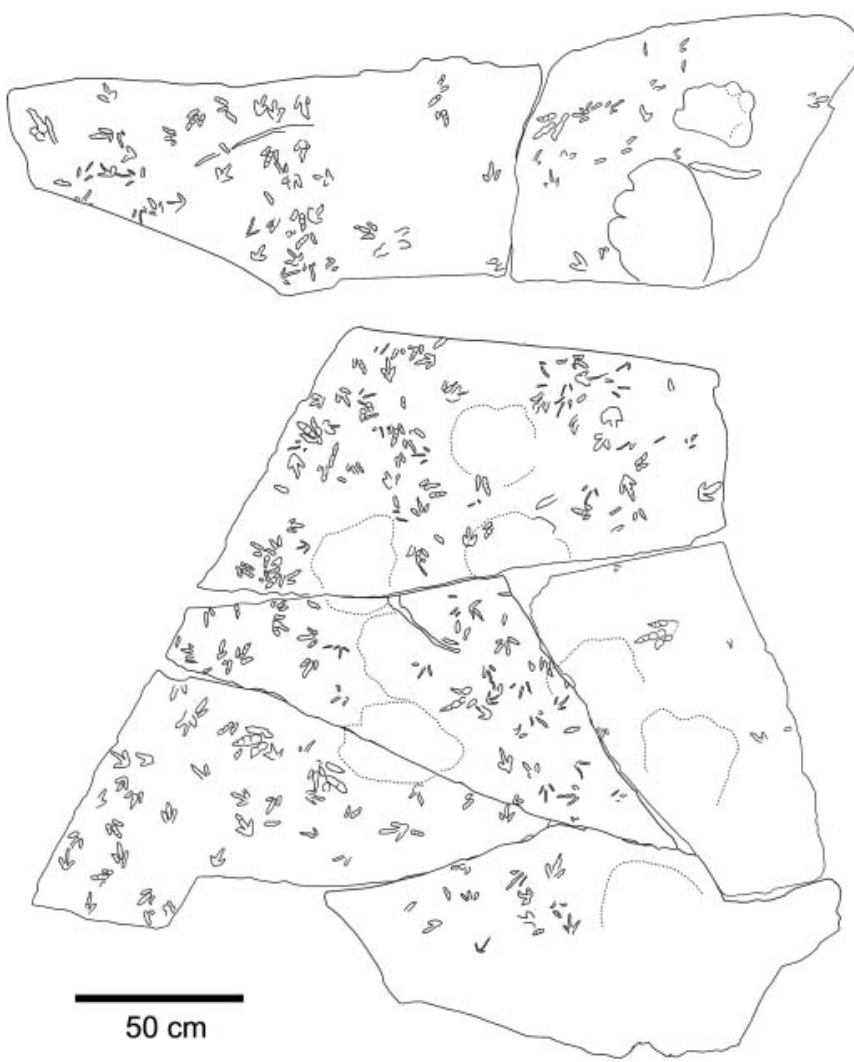

FIG. 3. Overview of slabs (sketch) with theropod and sauropod footprints described herein.

Grallator, Eubrontes, Kayentapus, or Gigandipus (Lockley et al., 2013).

Grallator is a common, small ( $<15 \mathrm{~cm}$ long), narrow, tridactyl track type made by bipedal theropods. Digit III projects relatively farther cranially than the other digits, and the foot is narrower than in Eubrontes and Anchisauripus (length/width ratio $\geq 2$ ); the divarication of the outer digits ranges from $10^{\circ}$ to $30^{\circ}$ (Hitchcock, 1858; Lull, 1953; Olsen et al., 1998). In terms of the number of specimens and named ichnospecies, Grallator is a common ichnogenus that encompasses many

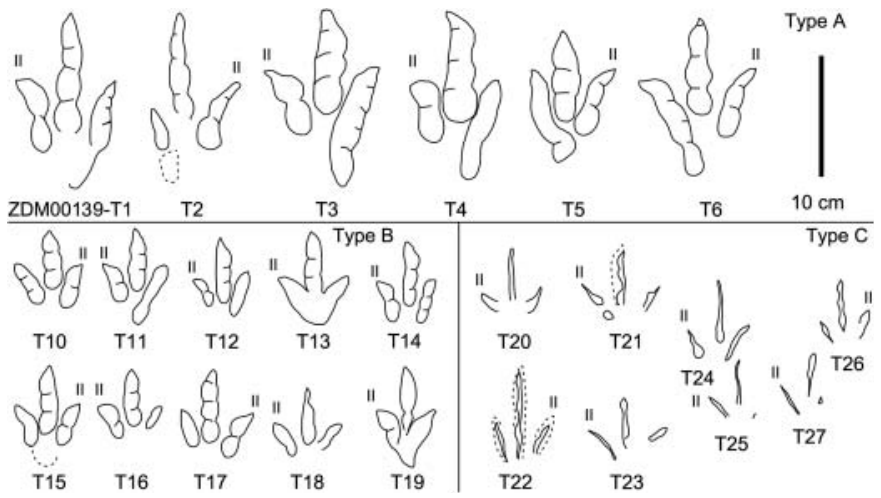

FIG. 4. A-C. Sketches of theropod footprints from the Hejie tracksite with the different morphotypes.

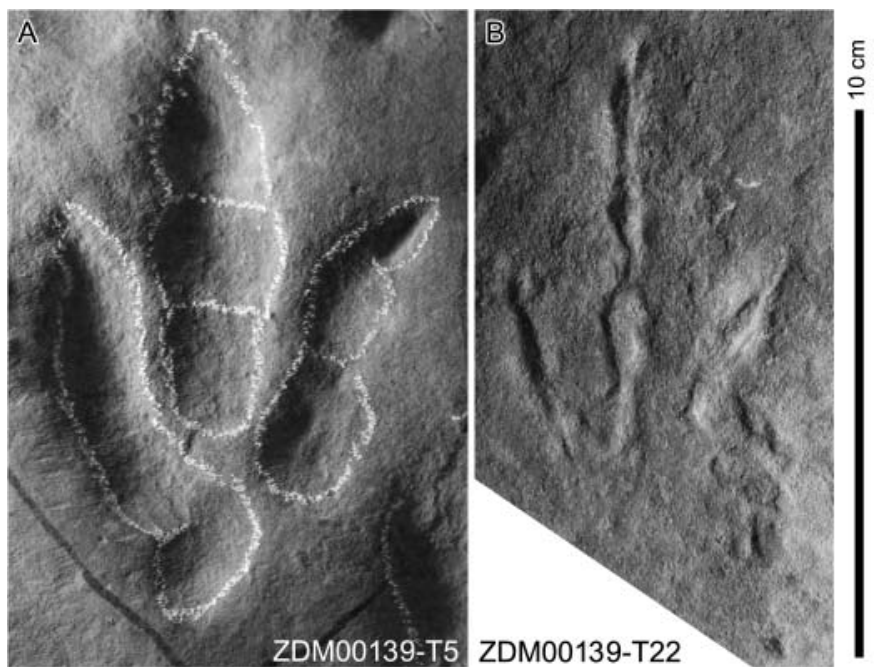

FIG. 5. A., B. Photographs with details of theropod footprints referring to morphotypes A., C. Notice slender convex epirelief in the interior portion of concave moulds in $\mathrm{B}$.

small, predominantly Late Triassic and Early Jurassic theropod tracks (Olsen et al., 1998; Lockley, 1991).

By some features, the Hejie tracks are similar to Grallator. Characteristics shared by the Hejie tracks and Grallator include the small-size, digit III being always longest, and the high length/width ratio. However, the Hejie tracks have several morphological characteristics that are different from typical Grallator, such as the considerable divarication angles ( $51^{\circ}$ between digits II and IV) and a metatarsophalangeal pad of digit IV that lies nearly in line with the long axis of digit III, slightly resembling Jialingpus from the Late Jurassic of Sichuan (Zhen et al., 1983; Xing et al., in press b). However, Jialingpus has an elongate and swollen metatarsophalangeal region, whereas the metatarsophalangeal pad of the Hejie tracks is comparably smaller. As noted below these different morphological characteristics may be in part due to preservational phenomena. Thus, as done here, caution must be exercised in drawing formal ichnotaxonomic conclusions.

Using the stride length equation of Alexander (1976) (SL/h $=2.15$ ) and the hip height equation of Henderson (2003) (hip height $\approx 4 \times$ footprint length), the trackmaker of the Hejie theropod tracks (T1-T3) is estimated to have been trotting at $2.14 \mathrm{~m} / \mathrm{s}$. Using the average hip height to body length ratio of 1:2.63 (Xing et al., 2009), the trackmaker of the type A tracks is estimated to have been $1.43 \mathrm{~m}$ in length, and that of the type $\mathrm{B}$ tracks to have been $0.75 \mathrm{~m}$ in length. Both trackmakers are small-sized theropods, suggesting that at least two distinct small theropods were contemporaneous in the Lower Jurassic Zigong area. Even in the Middle and Upper Jurassic of Sichuan, where skeletal fossils of large theropods are abundant, such as those of Yangchuanosaurus (Dong, 1978, 1983), Szechuanosaurus (Young, 1942), and Leshansaurus (Li et al., 2009), no small theropods have been discovered. 
TABLE 1

Measured data (in $\mathrm{cm}$ ) of the theropod tracks from Hejie tracksite, Zigong, China

\begin{tabular}{lrrrrrrrrr}
\hline Specimen ZDM00129- & ML & MW $^{*}$ & LD II & LD III & LD IV & II-III & III-IV & II-IV & ML/MW \\
\hline T1 & 14.6 & 8.2 & 6.4 & 10.0 & 9.6 & $26^{\circ}$ & $23^{\circ}$ & $49^{\circ}$ & 1.78 \\
T2 & 14.1 & 7.6 & 6.1 & 8.6 & 6.4 & $30^{\circ}$ & $22^{\circ}$ & $52^{\circ}$ & 1.86 \\
T3 & 14.7 & 9.6 & 6.3 & 8.7 & 10.3 & $29^{\circ}$ & $24^{\circ}$ & $53^{\circ}$ & 1.53 \\
T4 & 14.0 & 7.3 & 5.1 & 9.3 & 8.8 & $24^{\circ}$ & $25^{\circ}$ & $49^{\circ}$ & 1.92 \\
T5 & 10.9 & 6.9 & 6.2 & 7.4 & 8.0 & $29^{\circ}$ & $20^{\circ}$ & $49^{\circ}$ & 1.58 \\
T6 & 13.1 & 9.7 & 6.2 & 8.0 & 9.1 & $27^{\circ}$ & $32^{\circ}$ & $59^{\circ}$ & 1.35 \\
T10 & 6.5 & 5.5 & 4.0 & 4.8 & 3.9 & $32^{\circ}$ & $43^{\circ}$ & $75^{\circ}$ & 1.18 \\
T11 & 8.0 & 5.2 & 3.5 & 5.2 & 5.4 & $27^{\circ}$ & $28^{\circ}$ & $56^{\circ}$ & 1.54 \\
T12 & 6.6 & 4.5 & 2.5 & 5.4 & 3.9 & $40^{\circ}$ & $36^{\circ}$ & $76^{\circ}$ & 1.47 \\
T13 & 7.7 & 5.7 & 2.7 & 5.0 & 2.5 & $36^{\circ}$ & $36^{\circ}$ & $72^{\circ}$ & 1.35 \\
T14 & 6.8 & 4.8 & 3.6 & 5.3 & 3.7 & $36^{\circ}$ & $32^{\circ}$ & $68^{\circ}$ & 1.42 \\
T15 & 8.4 & 5.3 & 3.7 & 5.8 & 3.2 & $26^{\circ}$ & $29^{\circ}$ & $55^{\circ}$ & 1.58 \\
T16 & 5.7 & 5.2 & 3.8 & 4.6 & 2.3 & $52^{\circ}$ & $49^{\circ}$ & $101^{\circ}$ & 1.10 \\
T17 & 7.4 & 6.0 & 4.3 & 6.0 & 3.4 & $46^{\circ}$ & $36^{\circ}$ & $82^{\circ}$ & 1.23 \\
T18 & 5.6 & 5.6 & 3.2 & 4.7 & 2.7 & $47^{\circ}$ & $52^{\circ}$ & $99^{\circ}$ & 1.0 \\
T19 & 8.3 & 4.9 & 3.3 & 5.4 & 5.2 & $27^{\circ}$ & $27^{\circ}$ & $54^{\circ}$ & 1.69 \\
T20 & 5.5 & 4.9 & 1.7 & 4.3 & 2.1 & $56^{\circ}$ & $47^{\circ}$ & $103^{\circ}$ & 1.12 \\
T21 & 6.2 & 6.4 & 3.8 & 5.0 & 2.3 & $50^{\circ}$ & $51^{\circ}$ & $101^{\circ}$ & 0.97 \\
T22 & 8.0 & 4.9 & 3.4 & 7.5 & 4.0 & $36^{\circ}$ & $33^{\circ}$ & $69^{\circ}$ & 1.63 \\
T23 & 5.2 & 6.4 & 3.3 & 4.1 & 1.7 & $51^{\circ}$ & $69^{\circ}$ & $120^{\circ}$ & 0.81 \\
T24 & 6.8 & 5.1 & 2.5 & 5.2 & 3.6 & $44^{\circ}$ & $43^{\circ}$ & $87^{\circ}$ & 1.33 \\
T25 & 4.8 & - & - & 3.6 & - & $53^{\circ}$ & - & - & - \\
T26 & 5.2 & 4.2 & 2.5 & 4.3 & 2.0 & $50^{\circ}$ & $38^{\circ}$ & $88^{\circ}$ & 1.24 \\
T27 & 5.2 & 8.2 & 2.9 & 3.7 & 9.6 & $50^{\circ}$ & - & - & 0.63 \\
\hline
\end{tabular}

* Measured as the distance between the tips of digits II and IV.

Abbreviations: ML: maximum length; MW: maximum width*; LD I: length of digit I; LD II: length of digit II; LD III: length of digit III; LD IV: length of digit IV; I-II: angle between digits I and II; II-III: angle between digits II and III; III-IV: angle between digits III and IV; 1/w: ML/MW; - : measurement not possible or not applicable.

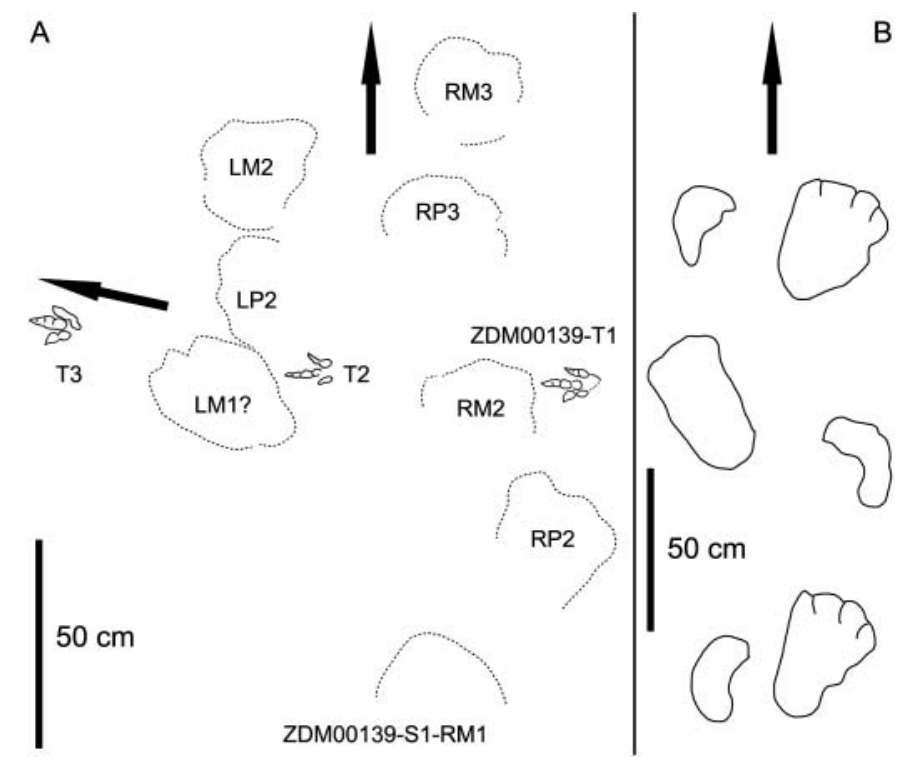

FIG. 6. A. Sketch of Hejie sauropod and theropod trackways described herein. B. Sketch of Gulin sauropod trackway. 


\section{A Note on Theropod Track Preservation}

Theropod track type $\mathrm{C}$ is, at first sight, morphologically different from many other theropod tracks, including Types A and $\mathrm{B}$, due to apparently representing a very gracile trackmaker with slender toes. As shown in Figure 5B, track ZDM00139-T22 reveals raised (convex) narrow areas of positive relief within the fainter outline that defines the track margin. Such preservation has been noted elsewhere, For example, similar tracks have been reported from a site in the Lower Jurassic of Eastern Utah known as the Lisbon oilfield site (Lockley and Hunt, 1995; Lockley and Gierlinski, 2006), where it is associated with typical Grallator tracks. Similar preservation occurs in the type of Magnoavipes lowei from the "mid" Cretaceous of Texas (Lee, 1997, fig 5a). According to Lockley et al. (2001), while Magnoavipes is a distinctive ichnogenus indicating a slender, bird-like theropod (possibly an ornithomimosaur) with wide digit divarication, the Texas ichnospecies (M. lowei) is somewhat ill-conceived because it is poorly preserved, without the digital pad traces seen in other better-preserved examples of Magnoavipes. Instead the Texas ichnospecies digit traces are characterized by very slender raised ridges that appear to be the result of unusual preservation. Possibly this is the result of collapse of a very narrow concave track in such a way as to allow the two walls merge as a raised (convex) positive relief feature.

In all these cases, the question arises, as to how the convex features were created and preserved. However, little detailed analysis of the sedimentary structures associated with these tracks has been undertaken, so likely explanations remain conjectural. The explanation suggested above for the Texas Magnoavipes tracks is not adequate to explain the Zigong tracks because there is no clear evidence that the positive relief in the middle of the tracks is the result of the collapse of a narrow track to merge the walls. Rather, the positive feature appears to indicate a compacted area in the middle of the tracks that has survived the preservation and exhumation process, so as to still reveal the main features of the pad traces. It is not unusual for tracks to be preserved with a certain amount of filling material. In some cases the fill may be the result of deposition of a sedimentary layer above the tracked surface. In other cases the fill may be the residue of the compacted layer on which the animal stepped, pushing the layer into the underlying layer which also registered the track. Given that the type $\mathrm{C}$ tracks from Zigong could be preservational variants of the Type B tracks we have not attached any ichnotaxonomic significance to the difference between types B and C. Instead we draw attention to the need for more detailed study of the impact trackmakers have in creating different track morphologies under different substrate conditions.

\section{Sauropod Tracks}

Material: A trackway composed of eight manus and pes natural-mold tracks, cataloged as ZDM00139-S1-RM1-RM3,
LP2-RP3 ("M" and "P" appended to the end of the specimen number indicate manus and pes, respectively); and a nearly complete manus-pes set of natural-mold tracks, cataloged as ZDM00139-S2-LM1, LP1.

Locality and horizon: Same as above.

Description and comparison: ZDM00139-S1 (Fig. 6A) consists of eight poorly preserved tracks, probably undertracks, with only the partial margins of the tracks discernable. Manus prints S1-RM1-RM3 are subcircular, their average length:width ratio is 0.84 , with an average length of $23 \mathrm{~cm}$, and an average width of $26 \mathrm{~cm}$. A few indentations within RM2 and LM2 could be delineations of digits. Pes prints S1RP2-LP2 -RP3 lack heel impressions. The anterior portion of the tracks range from 15 to $19 \mathrm{~cm}$ in length and from 26 to $30 \mathrm{~cm}$ in width. They have three equally distinct impressions, which probably represent digits I-III. The pes prints are significantly rotated outwards, although the angle is difficult to determine. The pace angulation is $66^{\circ}$ in the manus of RM2LM2-RM3 and $64^{\circ}$ in the pes of RP2-LP2-RP3. Considering that the pes print lacks a heel, the gauge of ZDM00139-S1 is relatively narrow. As in other sauropod tracks, the manus impressions are rotated $44^{\circ}$ (range from $27^{\circ}$ to $60^{\circ}$ ) outward from the trackway axis.

ZDM00139-S2-LM1 and LP1 (Figs. 7A and B) are wellpreserved and probably pertain to the $\mathrm{S} 1$ trackway, but this is not certain. The manus print ZDM00139-S2-LM1 is sub-circular, $19.8 \times 27.4 \mathrm{~cm}$ in length and width. The length:width ratio of LM1 is 0.72 . Discernible claw marks are absent. A round mark situated at the medial side of the manus imprint could delineate the foot callosity of digit I. The metacarpophalangeal region is posteriorly concave. The pes print LP1 shows
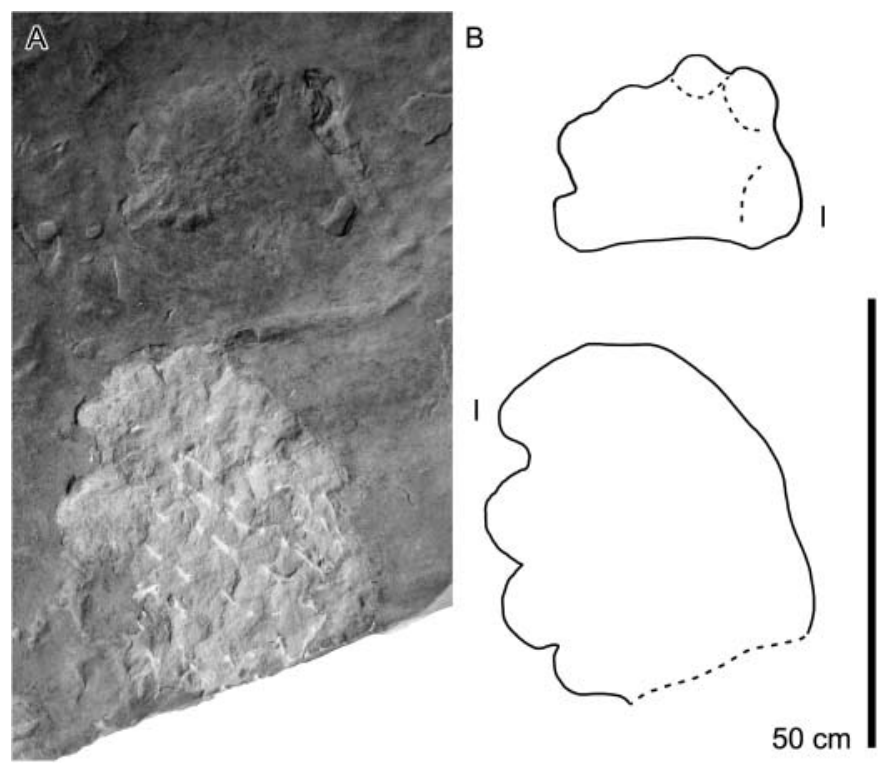

FIG. 7. A., B. Photograph and sketch of well-preserved pes-manus set ZDM00139-S2-LM1 and LP1. 
IV distinct digit traces and has an oval shape; its width is $29 \mathrm{~cm}$, and the distance to LM1 $7.6 \mathrm{~cm}$. The trace of the heel area is missing. Digits I, II, III have well-developed laterally directed claw marks. Digit IV has a small nail mark or depression made by a small ungual or foot callosity.

Discussion: Most sauropod trackways from China have been referred to Brontopodus (Lockley et al., 2002), though a few individual tracks have been referred to as Parabrontopodus-like (Xing et al., 2010). Chronologically, Parabrontopo$d u s$ ranges from the Early Jurassic $(P$. isp. [Niedźwiedzki and Pieńkowski, 2004]) through the Late Jurassic (P. mcintoshi [Lockley et al., 1994] and "Iguanodonichnus frenki" [Moreno and Benton, 2005]) to the Early Cretaceous (P. distercii [Meijide Fuentes et al., 2001]), being generally rate in the Cretaceous (Lockley et al., 1994).

The Hejie tracks are similar to Parabrontopodus in the following features: narrow gauge trackway, wide pes prints with anteriorly (or outwardly) directed claw or digit marks (Lockley et al., 1994, Santos et al., 2009). However, the Hejie tracks lack the crescent shaped manus prints, and the high heteropody. Due to incomplete material and insufficient quantity, further comparison is difficult.

The previously discovered sauropod material from the Ziliujing Formation include sauropodomorph skeletal fragments yielded from the Da'anzhai Member at Zigong area (Dong, 1984; Peng et al., 2005), several sauropod trackways from Gulin (Xing, 2010), and skeletons of the basal sauropod Gongxianosaurus from the Dongyuemiao Member (He et al., 1998, Luo and Wang, 2000). However, there is no sauropod record from the intermediate Ma'anshan Member. The discovery of the Hejie sauropod tracks fills in this gap.

Relatively very few unequivocal examples of sauropod tracks are known in Early Jurassic strata worldwide (Lockley et al., 1994). The Gulin sauropod trackways are well-preserved (Xing, 2010), but lack detailed descriptions. Taking one of these trackways as an example, it represents a typical wide-gauge sauropod trackway. The Gulin sauropod tracks (Fig. 6B) show a high degree of heteropody (manus prints $17 \times 27 \mathrm{~cm}$, pes prints $40 \times 27 \mathrm{~cm}$ ), the manus and pes prints have four distinct large claw marks and are rotated outward, the rotation angle for the manus and pes prints being $45^{\circ}$ and $28^{\circ}$, respectively. They are similar to Breviparopus /Parabrontopodus in morphology (Lockley et al., 1994; Santos et al., 2009). Both the Gulin sauropod trackways and the Hejie sauropod tracks have four distinct large claw marks; however, the morphology of the manus prints is different.

The Dazu sauropod trackways from the Zhenzhuchong Formation are probably the oldest sauropod trackways known from Asia (Yang and Yang, 1987; Lockley and Matsukawa, 2009). One of the authors (ML) visited this locality and obtained a tracing of the tracks (Lockley and Matsukawa 2009; Fig. 7). The lead author (LX) visited this locality in 2011. No further descriptions of the Dazu sauropod trackways have been published. In general, the Dazu trackways reflect a single wide gauge sauropod making a sharp left turn. They are similar to Brontopodus in morphology, which differs from the narrow gauge trackway of the Hejie sauropod trackways.

\section{THE TRACK-RICH SICHUAN BASIN}

As indicated below, there are multiple track-bearing formations in the early Mesozoic (pre Cretaceous) sequences of the Sichuan Basin, as well as many important Cretaceous trackbearing units in the region. In this section we present a summary of Late Triassic and Jurassic track occurrences, as well as important body fossil occurrences.

\section{Late Triassic and Jurassic Dinosaur Tracks of the Sichuan Basin}

Triassic deposits are relatively scarce in the Sichuan Basin, and Triassic outcrops in the western part of the basin mainly belong to the Late Triassic (Rhaetian) Xujiahe Formation (Peng et al., 2005; Qiao et al., 2012). Peng et al. (2005) described the dinosaur fauna from the Zigong area, establishing a biostratigraphic sequence based on vertebrate fossils. This scheme identifies two formations (Zhenzhuchong and Ziliujing) as Lower Jurassic, two (Xintiangou and Xiashaximiao) as Middle Jurassic and three (Shangshaximiao, Suining and Penglaizhen) as Upper Jurassic.

\section{Xujiahe Formation}

\section{Theropod tracks}

Eubrontes- and Grallator-sized footprints of theropods are known from two localities in the Xujiahe Formation of the Sichuan Basin (Yang and Yang, 1987; Wang et al., 2005). The larger ones that constitute a partial trackway were named as Pengxianpus cifengensis; the smaller theropod footprints are also part of an incomplete trackway. They are tentatively referred here to theropod footprints indet. (Xing et al., 2013a).

\section{Archosaur/?sauropodomorph tracks}

A bipedal trackway from the Longguan tracksite located in the uppermost part of the Upper Triassic Xujiahe Formation. These footprints slightly resemble the ichnogenus Eosauropus from North America and Europe, assigned to facultative bipedal sauropodomorphs (Xing et al., in press a).

\section{Zhenzhuchong Formation}

\section{Dinosaur body fossils}

Dong et al. (1983) have described several fragmentary Lufengosaurus remains from the Zhenzhuchong Formation in the Weiyuan area. The Zhenzhuchong vertebrate fauna 
includes the typical Lufengosaurus (prosauropod) fauna (Peng et al., 2005).

\section{Sauropod tracks}

Yang and Yang (1987) reported a wide gauge sauropod trackway from the Dazu tracksite in the Zhenzhuchong Formation. They were later noted by Matsukawa et al. (2006) and briefly described by Lockley and Matsukawa (2009, fig. 7). This may be the oldest sauropod trackway known from China.

\section{Theropod tracks}

According to Gao (2007), the ichnotaxon Weiyuanpus zigongensis also originates from the Zhenzhuchong Formation. Weiyuanpus is probably a junior synonym of the more widespread theropod ichnotaxon Eubrontes (Lockley and Matsukawa, 2009; Lockley et al., 2013).

\section{Ziliujing Formation}

The Ziliujing Formation was divided into the Dongyuemiao, Maanshan, and Daanzhai members (Peng et al., 2005).

\section{Dinosaur body fossils}

Important discoveries including prosauropods, cf. Lufengosaurus from the Daanzhai Member in the Zigong area (Dong, 1984), the primitive sauropod Zizhongosaurus from Zizhong, Weiyuan and Neijiang (Dong et al., 1983; Li, 1998), Gongxianosaurus from the Dongyuemiao Member in the Gongxian area (Wang and Zhou, 2005), unnamed theropod material from the same site as Gongxianosaurus (Wang and Zhou, 2005).

\section{Sauropod tracks}

Xing (2010) reported extensive parallel sauropod trackways and scattered theropod tracks from the Daanzhai Member in the Gulin area, which are under further study. The narrowgauge trackway from the Hejie tracksite was described herein.

\section{Theropod tracks}

Several theropod tracks discovered in the Daanzhai Member in Gulin area (Xing, 2010). Small grallatorid tracks have been reported from the Ziliujing Formation at the Hejie tracksite by Peng et al. $(2005,2012)$ and here in this study.

\section{Xintiangou Formation}

\section{Theropod tracks}

A number of tracksites have been reported from this unit, including the Wu Ma Cun village sites A and B (Matsukawa et al., 2006). Site A is the type locality of the ichnotaxa
Zizhongpus wumanensis, Tuojiangpus shuinanensis, Chonglongpus hei, and Chuanchengpus wuhuangensis, and site B is the type locality of Megaichnites jizhaishiensis and Chongqingpus microiscus, all of which were described by Yang and Yang (1987). However, all ichnogenera are subjective junior synonyms of Grallator, Eubrontes and Kayentapus (Lockley and Matsukawa, 2009; Lockley et al., 2013).

\section{Ornithopod tracks}

The Nianpanshan site, another in the Xintiangou Formation, is according to Yang and Yang (1987) the type locality of Jinlijingpus nianpanshanensis, which Lockley et al. (2013) assigned to Eubrontes nianpanshanensis. Lockley and Matsukawa (2009) presented a map of this site, which produced the first Anomoepus trackways reported from China.

\section{Xiashaximiao Formation}

The former Shaximiao Formation is widely exposed in the Sichuan Basin. The Shaximiao Formation is currently divided into the Middle Jurassic lower part ("Xiashaximiao Formation" of Peng et al., 2005) and the Upper Jurassic upper part ("Shangshaximiao Formation" of Peng et al., 2005). The formalization as lower (= "xia") and upper (= "shang") Shaximiao formations is problematic because lithostratigraphic names are locations whereas the prefixes reflect the relative position in the stratigraphic column, and there is no place called for example "Xiashaximiao" (Lucas, 2013, personal communication). Therefore, we put these names in quotation marks here. It is characterized by a large thickness and monotonous lithology (Compiling Group of Continental Mesozoic Stratigraphy and Palaeontology in Sichuan Basin of China, 1982).

\section{Dinosaur body fossils}

The lower part (Xiashaximiao Formation) provided the Shunosaurus fauna, such as Szechuanosaurus and Gasosaurus (Theropoda), Shunosaurus, Datousaurus, and Omeisaurus (Sauropoda), Xiaosaurus and Agilisaurus (Ornithopoda), Huayangosaurus (Stegosauria) (Peng et al., 2005).

\section{Shangshaximiao Formation}

This is the most widely distributed unit in the Sichuan Basin and characterized by the red colour. It is rich in dinosaur and other vertebrate fossils.

\section{Dinosaur body fossils}

The Shangshaximiao Formation provided the Mamenchisaurus fauna such as Yangchuanosaurus, Szechuanosaurus and Leshansaurus (Theropoda), Mamenchisaurus and Omeisaurus 
(Sauropoda), Gongbusaurus (Ornithopoda), Gigantspinosaurus and Tuojiangosaurus (Stegosauria) (Peng et al., 2005; Li et al., 2009).

\section{Theropod tracks}

The Nan'an site, and type locality of Chongqingpus nananensis, has yielded a large sample of theropod tracks from the heart of Chongqing Municipality (Yang and Yang, 1987). C. nananensis is a medium-sized track (mean track length $\sim 29 \mathrm{~cm}$ ) that may better be assigned to the ichnogenus Kayentapus (Xing et al., 2013b). The Jinji tracksite has yielded a single long theropod trackway of a robust form tentatively labeled cf. Therangospodus (Xing et al., 2013b).

\section{Ornithopod tracks}

Some small tridactyl tracks yielded from the Nan'an tracksite are attributed to cf. Anomoepus, among them some that preserved a hallux trace (Xing et al., 2013b). The common track types from this unit at the Nan'an site resemble Kayentapus and Anomoepus, which are characteristic of the Lower Jurassic, especially in North America where they are abundant.

\section{Suining Formation}

\section{Dinosaur body fossils}

Mamenchisaurus anyueensis represented by teeth and postcranial skeletons of more than ten individuals in the Suining Formation (He et al., 1996). Additional records are some adult and juvenile sauropods and theropods yielded from the Longjiaya fossil site in Anyue County (Kan et al., 2005), but these lack detailed descriptions. Theropod teeth and sauropod remains (Mamenchisaurus Fauna) are known from the Suining Formation in the Qijiang Dinosaur National Geological Park, located in Qijiang County, south of Chongqing Municipality (Miyashita and Xing, 2012).

\section{Penglaizhen Formation}

\section{Sauropod body fossils}

Sauropod fossils from the Penglaizhen Formation are rare. Mamenchisaurus sp. (Wang et al., 2003), discovered in Jianyang, may be the stratigraphically latest record of Mamenchisaurus in China (Suteethorn et al., 2012).

\section{Theropod tracks}

Zhen et al. (1983) described a theropod track with a metatarsal impression, named Jialingpus yuechiensis from the Penglaizhen Formation in Huanglong, Yuechi County, Guangan City.
Although dinosaur excavation and research in Sichuan Province have a long history of 90 years, intensive excavation only occurred at the Dashanpu site of Zigong in 1979-84 (Peng et al., 2005). In contrast, excavations at other sites have been limited. In recent years, discoveries of dinosaur tracks have provided a lot of information about the paleoecology of dinosaurs in Sichuan Province (Fig. 8).

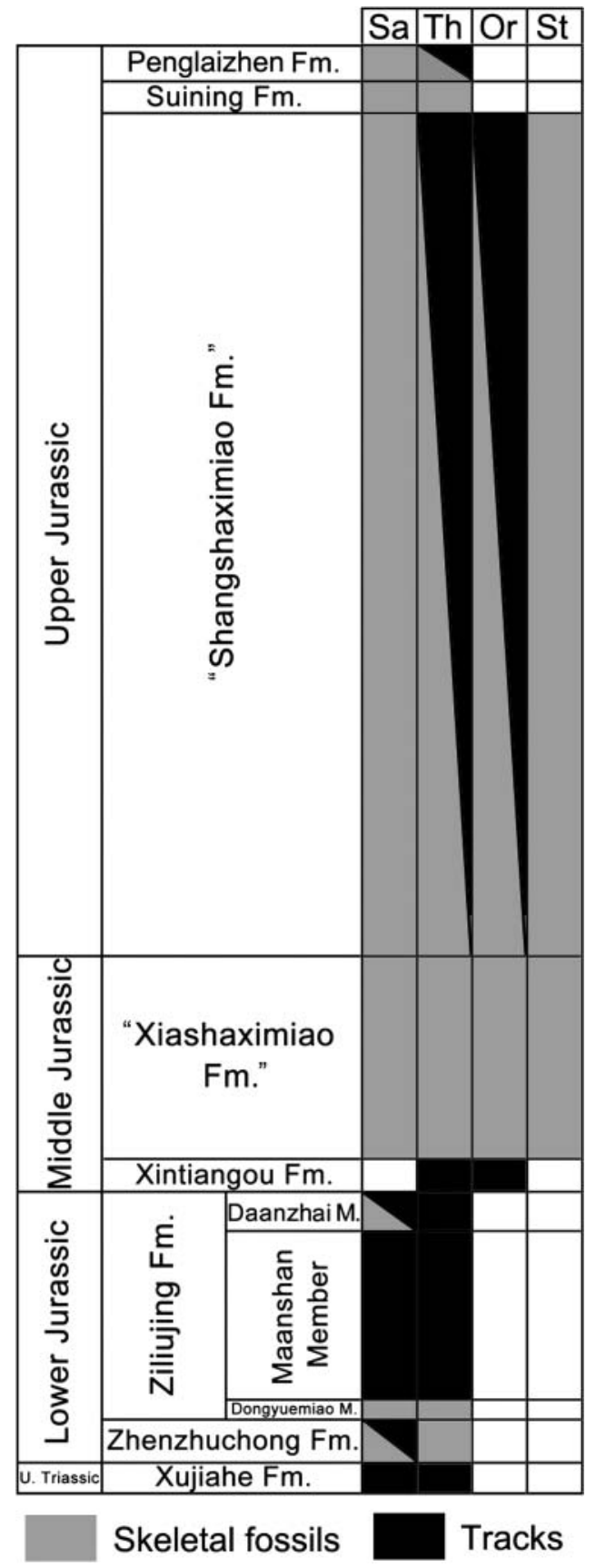

FIG. 8. Stratigraphic distribution of dinosaur body fossils and tracks from the Late Triassic and Jurassic of the Sichuan Basin (stratigraphy modified from Peng et al., 2005). Or: Ornithopoda; Sa: Sauropoda; St: Stegosauria; Th: Theropoda 
With the exception of that no sauropodomorphs were found thus far in the Middle Jurassic Xintiangou Formation, sauropod tracks and body fossils are widely distributed in Late Triassic-Jurassic deposits of the Sichuan Basin. First basal sauropodomorphs occur in the Lower Jurassic Zhenzhuchong Formation. Their last appearance is in the top of the Lower Jurassic Ziliujing Formation. A sauropodomorph origin of the indeterminate trackway from the Upper Triassic Xujiahe Formation (Xing et al., in press a) is discussed. Body fossils suggest that basal sauropodomorphs appeared in the Lower Jurassic Ziliujing Formation and Eusauropoda in the Middle Jurassic Xiashaximiao Formation. However, the tracks (Dazu tracksite; Lockley and Matsukawa, 2009) suggest an earlier appearance in the Lower Jurassic Zhenzhuchong Formation. Remarkably, neither the Xiashaximiao Formation nor the Shangshaximiao Formation yielded any tracks. This is different from the Upper Jurassic Morrison Formation in North America, which contains abundant sauropod body fossils and tracks (Dodson et al., 1980; Lockley et al., 1998).

Sauropod tracks are common in low latitude coastal settings where carbonate substrates predominate, that is, where evaporation tends to exceed precipitation, but they appear to be rare in humid coastal settings where coalbearing facies are well-developed (Lockley et al., 1994b). However, in Asia sauropod tracks are quite common in isolated inland basins with red bed deposition, again, in many cases, indicating evaporation exceeding precipitation. Body fossils and tracks suggest that sauropodomorphs flourished in the Jurassic Sichuan Basin. Research on palynomorphs suggests that the environment and climate of the Lower Jurassic Sichuan Basin changed from river to lake and from warm and humid to dry tropical, respectively. The dry climate continued until the end of the Jurassic (Wang et al., 2008), which is consistent with the typical climate inferred for the sauropod habitats.

The Jurassic Sichuan Basin lacks skeletons of large-sized ornithopods. Whereas small ornithopod fossils are common in the Xiashaximiao and Shangshaximiao formations, ornithopod tracks such as Anomoepus occur earlier in the Middle Jurassic Xintiangou Formation.

Skeletons of small theropods are absent in the Jurassic of the Sichuan Basin as well. However, small theropod tracks appear in the Late Triassic Xujiahe Formation, the middle member of the Lower Jurassic Ziliujing Formation, and in the Middle Jurassic Xintiangou Formation. This suggests that small theropods were common in the Sichuan Basin between the Late Triassic and the Middle Jurassic.

Based on skeletal evidence, middle-large sized theropods first appeared in the Lower Jurassic Zhenzhuchong Formation and continuously flourished in the Jurassic, whereas footprints document an earlier occurrence in the Late Triassic (Xing et al., 2013a). No body fossils were yet found in the middleupper members of the Ziliujing and Xintiangou formations, whereas tracks are quite common.
A final point of interest is that, as in China and other parts of the world, the early Jurassic track record, like the Jurassic record in general, is heavily saurischian dominated, with even greater emphasis on non-avian theropod track occurrences. This general global trend of saurischian-dominated Jurassic faunas giving way to more ornithischian-dominated Cretaceous faunas is well-known if rarely analyzed in detail or explained in the context of evolutionary dynamics (Lockley, 2007). As indicated here, the Chinese track record, well represented in Sichuan, confirms the presence of heavily saurischian-dominated faunas. As noted by Matsukawa et al. (2006) in some parts of China saurischian-dominated faunas persist into the Cretaceous, where the non avian theropod component of the fauna is added to by track and skeletal evidence of avian theropods.

\section{CONCLUSIONS}

The footprint assemblage from the Ziliujing Formation of Zigong City enlarges the record of dinosaurs from the Lower Jurassic of this locality that was thus far restricted to a few skeletal remains and tracks. For the first time the presence of small theropods in the Jurassic of Zigong is proved by their footprints. Up to now only middle-large-sized individuals have been known by skeletal remains. The sauropod tracks are the first documents of the group in the Ma'anshan Member of the Ziliujing Formation. In general, saurischian-dominated assemblages are typical of the Jurassic, but can also be explained in terms of paleoenvironmental factors relating to low, tropical latitude and semi-arid environments of inland basins (Matsukawa et al., 2006). Bivalves yielded from the track locality indicate a tropical freshwater such as a shallow lake (Cai, 1986).

\section{ACKNOWLEDGMENTS}

The authors thank Gerard D. Gierliński (Polish Geological Institute, Poland) and Spencer Lucas (New Mexico Museum of Natural History and Science, USA) for his critical comments and suggestions on this paper. Detailed revisions by two anonymous reviewers greatly improved the final version and we are appreciative of their efforts.

\section{FUNDING}

This research was supported by The Zigong Dinosaur Museum, Sichuan Province.

\section{REFERENCES}

Alexander, R. M. 1976. Estimates of speeds of dinosaurs. Nature, 261: 129-130.

Compiling Group of Continental Mesozoic Stratigraphy and Palaeontology in Sichuan Basin of China. 1982. Continental Mesozoic Stratigraphy and Palaeontology in Sichuan Basin of China. People's Publishing House of Sichuan, Chengdu, China, 405 p. 
Dodson, P., Berensmeyer, A. K., Bakker, R. T., and McIntosh, J. S. 1980. Taphonomy of the dinosaur beds of the Jurassic Morrison Formation. Paleobiology, 6:208-232.

Dong, Z. 1984. A new prosauropod from Ziliujing Formation of Sichuan Basin. Vertebrata Palasiatica, 22:310-313 (in Chinese with English summary).

Dong, Z., Zhang, Y., Li, X., and Zhou, S. 1978. A new carnosaur from Yongchuan County, Sichuan Province. Chinese Science Bulletin, 23(5): 302-304.

Dong, Z., Zhou, S., and Zhang, Y. 1983. Dinosaurs from the Jurassic of Sichuan. Palaeontologica Sinica, New Series C, 162:1-136.

Gai, S. Y. 1986. Fresh-water fossil bivalves from Maanshan Member of Ziliujing Formation in Weiyuan, Sichuan. Acta Palaeontologica Sinica, 5:560 566 (in Chinese with English summary).

Gao, Y. H. 2007. New dinosaur footprint from Lower Jurassic of Weiyuan, Sichuan. Vertebrata PalAsiatica, 45:342-345 (in Chinese with English abstract).

He, X. L., Yang, S. H., Cai, K. J., Li, K., and Liu, Z. W. 1996. A new species of sauropod, Mamenchisaurus anyuensis sp. nov. Papers on Geosciences contributed to the 30th Geological Congress, China Economy Press, Beijing, China, 83-86.

He, X. L., Wang, C. S., Liu, S. Z., Zhou, F. Y., Liu, T. Q., Cai, K. J., and Dai, B. 1998. A new species of sauropod from the Early Jurassic of Gongxian Co., Sichuan. Acta Geologica Sichuan, 18:1-7.

Henderson, D. M. 2003. Footprints, trackways, and hip heights of bipedal dinosaurs - testing hip height predictions with computer models. Ichnos, 10:99-114.

Hitchcock, E. 1858. Ichnology of New England. A Report on the Sandstone of the Connecticut Valley, Especially its Fossil Foot Marks. William White, Boston, Massachusetts, USA, $220 \mathrm{p}$.

Kan, Z. Z., Liang, B., Wang, Q. W., and Zhu, B. 2005. Trace Fossils in the Suining and Penglaizhen Formations as Buried Places of Dinosaur Fossils in Anyue, Sichuan, and their environmental significance. Acta Geologica Sichuan, 25:68-71.

Lee, Y. N. 1997. Bird and dinosaur footprints in the Woodbine Formation (Cenomanian), Texas, Cretaceous Research, 18:849-846.

Li, F., Peng, G., Ye, Y., Jiang, S., and Huang, D. 2009. A new carnosaur from the Late Jurassic of Qianwei, Sichuan, China. Acta Geologica Sinica, 83:1203-1213.

Li, K., Zhang, Y. G., and Cai, K. J. 1999. The Characteristics of the Composition of the Trace Elements in Jurassic Dinosaur Bones and Red Beds in Sichuan Basin. Geological Publishing House, Beijing, 155 p.

Lockley, M. G. 1991. Tracking Dinosaurs. Cambridge University Press, New York, $238 \mathrm{p}$.

Lockley, M. G. 2007. The morphodynamics of dinosaurs, other archosaurs and their trackways: Holistic insights into relationships between feet, limbs and the whole body. In Bromley, R. and Melchor, R. (eds.), Ichnology at the crossroads: A multidimensional approach to the science of organism-substrate interactions. Society of Economic Paleontologists and Mineralogists Special Publication, 88:27-51.

Lockley, M. G. and Matsukawa, M. 1998. Lower Cretaceous vertebrate tracksites of East Asia. In Lucas, S. G., Kirkland, J. I., and Estep, J. W. (eds.), Lower and Middle Cretaceous terrestrial ecosystems. New Mexico Museum of Natural History and Science Bulletin, 14:135-142.

Lockley, M. G., Farlow, J. O., and Meyer, C. A. 1994a. Brontopodus and Parabrontopodus ichnogen. nov. and the significance of wide and narrowgauge sauropod trackways. Gaia, 10:135-146.

Lockley, M. G. and Gierlinski, G. 2006. Diverse vertebrate ichnofaunas containing Anomoepus and other unusual trace fossils from the Lower Jurassic of the western United States: Implications for paleoecology and palichnostratigraphy. New Mexico Museum of Natural History and Science, Bulletin, 37:175-191.
Lockley, M. G. and Hunt, A. P. 1995. Dinosaur Tracks and Other Fossil Footprints of the Western United States. Columbia University Press, New York, $338 \mathrm{p}$.

Lockley, M. G., Hunt, A. P., and Meyer, C. A. 1994b. Vertebrate tracks and the ichnofacies concept: implications for paleoecology and palichnostratigraphy. In Donovan, S. (ed.), The Palaeobiology of Trace Fossils, Wiley, Chichester, UK, 241-268.

Lockley, M. G., Wright, J., White D, Matsukawa, M., Li, J. J., Feng, L., and Li, H. 2002. The first sauropod trackways from China. Cretaceous Research, 23:363-381.

Lockley, M. G., Li, J., Li, R. H., Matsukawa, M., Harris, J. D., and Xing, L. D. 2013. A review of the tetrapod track record in China, with special reference to type ichnospecies: Implications for ichnotaxonomy and paleobiology. Acta Geologica Sinica, 87:1-20.

Lockley, M. G., Wright, J. L., and Matsukawa, M. 2001. A new look at Magnoavipes and so-called "big bird" tracks from Dinosaur Ridge (Cretaceous, Colorado). In Lockley, M. G. and Taylor, A. (eds.), Dinosaur Ridge: Celebrating a decade of discovery. Mountain Geologist, 38:137146.

Lucas, S. G. 2001. Chinese Fossil Vertebrates. Columbia University Press, New York, 375 p.

Lull, R. S. 1953. Triassic life of the Connecticut Valley. Bulletin of the Connecticut State Geology, Natural History Survey, 181:1-331.

Li, F., Peng, G. Z., Ye, Y., Jiang, S., and Huang, D. 2009. A new carnosaur from the Late Jurassic of Qianwei, Sichuan, China. Acta Geologica Sinica, 83(9):1203-1213.

Luo, Y. N. and Wang, C. S. 2000. A new sauropod, Gongxianosaurus, from the Lower Jurassic of Sichuan, China. Acta Geologica Sinica-English Edition, 74:132-136.

Matsukawa, M., Lockley, M. G., and Li, J. J. 2006. Cretaceous terrestrial biotas of East Asia, with special reference to dinosaur-dominated ichnofaunas: Towards a synthesis. Cretaceous Research, 27:3-21.

Meijide Fuentes, F., Fuentes Vidarte, C., and Meijiede Calvo, M. 2001. Primeras huellas de sauropodo en el Weald de Soria (Espana), Parabrontopodus distercii, nov. ichnoesp. In Proceedings of the 1st International Symposium about Paleontology of Dinosaurs and their environment. Actas de Las I Jornadas Internacionales Sobre Paleontologia de Dinosaurios y su Entorno, 407-415.

Miyashita, T. and Xing, L. D. 2012. A new sauropod from the Late Jurassic of Qijiang, China. In Xing, L. D. and Lockley, M. G. (eds.), Abstract Book of Qijiang International Dinosaur Tracks Symposium, Chongqing Municipality, China, November 29-30. Boulder Publishing, Taibei, China, 82-84.

Moreno, K. and Benton, M. J. 2005. Occurrence of sauropod dinosaur tracks in the Upper Jurassic of Chile (redescription of Iguanodonichnus frenki). Journal of South American Earth Sciences, 20:253-257.

Niedźwiedzki, G. and Pieńkowski, G. 2004. A dinosaur track association from the Early Jurassic deltaic deposits of Podole near Opatów, Poland. Geological Quarterly, 48:333-338.

Olsen, P. E., Smith, J. B., and McDonald, N. G. 1998. Type material of the type species of the classic theropod footprint genera Eubrontes, Anchisauripus and Grallator (Early Jurassic, Hartford and Deerfield basins, Connecticut and Massachusetts, U.S.A.). Journal of Vertebrate Paleontology, 18:586-601.

Peng, G. Z., Ye, Y., Gao, Y. H., Shu, C. K., and Jiang, S. 2005. Jurassic Dinosaur Faunas in Zigong. People's Publishing House of Sichuan, Chengdu, China, $236 \mathrm{p}$.

Peng, G. Z., Xing, L. D., Ye, Y., Klein, H., Gierliński, G. D., and Shu, C. K. 2012. Report on small-sized theropod tracks from the Early Jurassic Ziliujing Formation of Zigong City, Sichuan, China. In Xing, L. D. and Lockley, M. G. (eds.), Abstract Book of Qijiang International Dinosaur Tracks Symposium, Chongqing Municipality, China, November 29-30. Boulder Publishing, Taibei, China, 98-100. 
Pieńkowski, G., Popa, M. E., and Kędzior, A. 2010. Early Jurassic Sauropod footprints of the southern Carpathians, Romania: Palaeobiological and Palaeogeographical Significance. Earth Science Frontiers, 17(Special Issue):193-196.

Qiao, X. F., Guo, X. P., Li, H. B., Gou, Z. H., Su, D. C., Tang, Z. M., Zhang, W., and Yang. G. 2012. Soft-sediment deformations in the Late Triassic and the Indosinian Tectonic Movements in Longmenshan. Acta Geologica Sinica, 86:132-156.

Santos, V. F., Moratalla, J. J., and Royo-Torres, R. 2009. New sauropod trackways from the Middle Jurassic of Portugal. Acta Palaeontologica Polonica, 54(3):409-422.

Suteethorn, S., Le Loeuff, J., Buffetaut, E., Suteethorn, V., and Wongko, K. 2012. First evidence of a mamenchisaurid dinosaur from the Late Jurassic/Early Cretaceous Phu Kradung Formation of Thailand. Acta Palaeontologica Polonica, 58:459-469.

Wang, Z. X., Li, K., and Liu, J. 2003. Mamenchisaurus from Upper Jurassic of Jianyang, Sichuan. Journal of Chengdu University of Technology, Science and Technology Edition, 30:485-490.

Wang, Q. W., Kan, Z. Z., Liang, B., and Cai, K. J. 2005. Discovery of track fossils of dinosaurs in Late Triassic strata of Tianquan, Sichuan, China. Geological Bulletin of China, 24:1179-1180.

Wang, Q. W., Liang, B., and Kan, Z. Z. 2008. Paleoenvironmental Reconstruction of Mesozoic Dinosaur Faunas in Sichuan Basin. Geological Publishing House, Beijing, $189 \mathrm{p}$.

Xing, L. D., Harris, J. D., Feng, X. Y., and Zhang, Z. J. 2009. Theropod (Dinosauria: Saurischia) tracks from Lower Cretaceous Yixian Formation at Sihetun, Liaoning Province, China and possible track makers. Geological Bulletin of China, 28:705-712.
Xing, L. D., Harris, J. D., and Jia, C. K. 2010. Dinosaur tracks from the Lower Cretaceous Mengtuan Formation in Jiangsu, China and morphological diversity of local sauropod tracks. Acta Palaeontologica Sinica, 49:448460.

Xing, L. D., Klein, H., Lockley, M. G., Chen, W., Ye, Y., Matsukawa, M., and Zhang, J. P. 2013a. Earliest records of theropod and mammal-like tetrapod footprints in the Late Triassic of Sichuan Basin, China. Vertebrata PalasiAtica, 51:184-198.

Xing, L. D., Lockley, M. G., Chen, W., Gierliński, G. D., Li, J. J., Persons IV, W. S., Matsukawa, M., Ye, Y., Gingras, M. K., and Wang, C. W. 2013b. Two theropod track assemblages from the Jurassic of Chongqing, China, and the Jurassic stratigraphy of Sichuan basin. Vertebrata PalAsiatica, 51 107-130.

Xing, L. D., Peng, G., Marty, D., Ye, Y., Klein, H., Li, J., Gierliński, G. D., and Shu, C. in press a. An unusual trackway of a possibly bipedal archosaur from the Late Triassic of the Sichuan Basin, China. Acta Palaeontologica Polonica. doi:10.4202/app.2012.0087.

Xing, L. D., Lockley, M. G., Gierliński, G. D., Klein, H., Hu, S. M., Zhang, J. P., Ye, Y., and He, Y. P. in press b. Early Cretaceous nonavian theropod tracks from the southern margin of the Ordos Basin, China. Palaeoworld. doi:10.1016/j.palwor.2013.12.001.

Yang, X. L. and Yang, D. H. 1987. Dinosaur Footprints of Sichuan Basin. Sichuan Science and Technology Publications, Chengdu, China, $30 \mathrm{p}$.

Young, C. C. 1942. Fossil vertebrates from Kuangyuan, N. Szechuan. Bulletin of the Geological Society of China, 22:293-308.

Zhen, S. N., Li, J. J., and Zhen, B. M. 1983. Dinosaur footprints of Yuechi, Sichuan. Memoirs of Beijing Natural History Museum, 25, 1-19. 